\title{
Clinicopathological evaluation of benign neck masses with emphasis on correlation of preoperative ultrasound and cytology with postoperative histopathology in tertiary care hospital
}

\author{
Priyanka Garud $^{1 *}$, Surendra Gawarle ${ }^{2}$, Prashant Keche ${ }^{3}$
}

Department of ENT, ${ }^{1}$ SRTR Government Medical College, Ambajogai, ${ }^{2}$ Shri Vasantrao Naik Government Medical College, Yavatmal, ${ }^{3}$ Government Medical College and Cancer Hospital, Aurangabad, Maharashtra, India

Received: 07 January 2019

Revised: 14 April 2019

Accepted: 15 April 2019

\section{*Correspondence:}

Dr. Priyanka Garud,

E-mail: priyanka.garud04@gmail.com

Copyright: (C) the author(s), publisher and licensee Medip Academy. This is an open-access article distributed under the terms of the Creative Commons Attribution Non-Commercial License, which permits unrestricted non-commercial use, distribution, and reproduction in any medium, provided the original work is properly cited.

\begin{abstract}
Background: Benign neck mass is a common clinical condition which an ENT clinician routinely encounters. Commonly presenting benign neck masses occur within lymph nodes, thyroid, parotid and other salivary glands. Less common pathologies presenting as neck swellings are from thyroglossal cysts, branchial cleft cysts, carotid body tumors, cystic hygromas, pharyngeal pouch abnormalities and lumps of skin appendages.

Methods: This is prospective observational based study. Duration of study is $1 \mathrm{yr} 6$ months. All palpable neck masses which are clinically diagnosed as benign were selected.

Results: Study was conducted in Shri Vasantrao Naik Government Medical college, Yavatmal of 123 patients out of which 84 were thyroid swellings, 18 were salivary gland swellings and 21 were other swellings out of which 9 were lymph node swellings. $80.48 \%$ were female patients and $19.51 \%$ were male patients. Maximum number of patients were between the age group 31-40 years $(28.45 \%$ ) followed by $26.05 \%$ in $41-50$ years. This is $1 \mathrm{yr} 6 \mathrm{months}$ observational study of epidemiological and clinicopathological spectrum and outcome of management of benign neck masses. This study also determines the histopathological correlation and accuracy of FNAC in the diagnosis of benign neck masses.

Conclusions: We conclude from present study, that fine needle aspiration cytology is a safe, simple and more accurate than USG that can be done in diagnosing wide range of neck swellings. Probably USG guided fine needle aspiration cytology will be better investigation one can ask for. However confirmatory and accurate diagnosis is given by histopathology.
\end{abstract}

Keywords: Thyroid, FNAC, Benign

\section{INTRODUCTION}

Benign neck mass is a common condition routinely encountered. The first goal is to determine if the mass is malignant or benign. Etiologies can be grouped according to whether the onset/duration is acute (e.g., infectious), subacute (e.g., squamous cell carcinoma), or chronic (e.g., thyroid), and further narrowed by patient demographics.
While infections cause most of the neck masses in children, most persistent neck masses in adults are neoplasms. ${ }^{2}$

Due to the availability of high frequency probes role of ultrasonography (USG) in evaluation of neck region is becoming increasingly important, which permit visualization of more anatomical and pathological details. $^{3}$ High resolution B- mode sonography has 
improved in the past few years and has become a very valuable tool in the diagnosis of the disease of the head and neck. Ultrasonography is far more sensitive than palpation because it detects nodules of any size in up to $67 \%$ of the general population. ${ }^{4}$

Fine needle aspiration cytology (FNAC) is a simple, quick and cost effective method to sample superficial masses in the neck. This technique is performed in the outpatient clinic. Masses located within the region of head and neck including salivary glands and thyroid masses can be readily diagnosed using this technique. ${ }^{5}$ There is no evidence suggesting that the tumor spreads through the skin track created by the fine hypodermic needle used in this technique. ${ }^{6}$ FNAC is useful in diagnosis of salivary gland tumor where it can differentiate between a benign and malignant tumor with $90 \%$ accuracy. FNAC is not substitute for histopathology, especially in determination of nodal architecture in lymphoma, follicular thyroid tumor, intracapsular spread in squamous carcinoma or in the distinction of pleomorphic from monomorphic adenoma. $^{7}$

The purpose of this study is to evaluate the efficacy of USG and FNAC in diagnosis of neck masses.

\section{METHODS}

\section{Study design}

This is prospective observational based study. Study was carried out from January 2016 till June 2017.Sample size is 123 patients of all age group. Samples were selected attending ENT OPD of our hospital.

\section{Inclusion criteria}

All palpable neck masses which are clinically diagnosed as benign.

\section{Exclusion criteria}

Following were exclusion criteria of our study:

- Malignant neck masses.

- Acute neck space infections.

- Neck abscess.

- Immnunocompromised host.

- Tubercular lymphadenopathy.

All patients clinically diagnosed as benign, attending ENT OPD were selected and checked. These swellings were not hard, not fixed to surrounding structure, not associated with complications like nerve palsy. According to proforma history was taken and clinical examination was done. USG and FNAC was carried on OPD basis. After taking informed consent patients underwent surgical procedure, and histopathological reports were compared with USG and FNAC reports.

\section{Statistical analysis}

The statistical data was entered in MS excel 2007 and analysed using SPSS16.0 version. Results on continuous measurements are presented on mean SD (min-max) and results on categorical measurements are presented in number (\%). Diagnostic statistics i.e., sensitivity, specificity, and accuracy have been computed to find the correlation of USG and FNAC in diagnosis of benign neck masses.

\section{RESULTS}

It was found in present study that $87 \%$ of patients were of rural population and $13 \%$ of patients belonged to urban population.

Table 1: Age distribution of patients studied.

\begin{tabular}{|lll|}
\hline Age in years & No of patients & Percentage $(\%)$ \\
\hline $\mathbf{1 - 1 0}$ & 9 & 7.31 \\
\hline $\mathbf{1 1 - 2 0}$ & 10 & 8.13 \\
\hline $\mathbf{2 1 - 3 0}$ & 21 & 17.07 \\
\hline $\mathbf{3 1 - 4 0}$ & 35 & 28.45 \\
\hline $\mathbf{4 1 - 5 0}$ & 32 & 26.05 \\
\hline $\mathbf{5 1 - 6 0}$ & 6 & 4.87 \\
\hline $\mathbf{6 1 - 7 0}$ & 6 & 4.87 \\
\hline $\mathbf{7 1 - 8 0}$ & 4 & 3.25 \\
\hline
\end{tabular}

The maximum number of benign neck swelling were in $31-40 y r s$ age group $(28.45 \%)$ and minimum were in 71 80 yrs age group which is $3.25 \%$.

Total 123 patients were studied out of which 84 patients were of thyroid swellings, 18 patients were of salivary gland swellings and 21 patients were of other neck swellings. For ease of our study we have categorized the swellings in three categories i.e., thyroid swellings, salivary gland swellings and other neck swellings. Tubercular lymphadenopathy and acute neck space infections is excluded in our study. Thyroid swellings were $35.71 \%$ in age group 31-40 yrs and $29 \%$ in age group 41-50 yrs. It was found that in present study maximum number of patients of salivary gland swellings were in age group of 41-50 yrs comprising 33.33\%. In our study of other neck swellings which includes swelling of chronic cervical lymphadenopathy, thyroglossal cyst, dermoid, lipoma etc, maximum number of patients were in age group of 1-10 yrs.

In gender wise study of our patients it was found that thyroid swellings is more common in females i.e., $90.47 \%$, whereas in salivary gland swellings equal gender distribution was found. Female preponderance was more in other neck swellings which includes cervical lymphadenopathy, thyroglossal cyst, dermoid, lipoma.

In present study of total 123 patients, $80.48 \%$ patients were females and $19.51 \%$ were males, as most of patients in the present study were of thyroid swellings which are more common in females. 
Table 2: Age wise distribution of different neck swellings.

\begin{tabular}{|lllllll|} 
Age in years & $\begin{array}{l}\text { No of thyroid } \\
\text { swellings }\end{array}$ & $\begin{array}{l}\text { \% of thyroid } \\
\text { swellings }\end{array}$ & $\begin{array}{l}\text { No. of } \\
\text { salivary gland } \\
\text { swellings }\end{array}$ & $\begin{array}{l}\text { \% of salivary } \\
\text { gland } \\
\text { swellings }\end{array}$ & $\begin{array}{l}\text { No. of other } \\
\text { swellings }\end{array}$ & $\begin{array}{l}\text { \% of other } \\
\text { swellings }\end{array}$ \\
\hline $\mathbf{1 - 1 0}$ & 0 & 0 & 1 & 5.55 & 8 & 38.09 \\
\hline $\mathbf{1 1 - 2 0}$ & 4 & 4.76 & 2 & 11.11 & 4 & 19.04 \\
\hline $\mathbf{2 1 - 3 0}$ & 14 & 16.66 & 3 & 16.66 & 4 & 19.04 \\
\hline $\mathbf{3 1 - 4 0}$ & 30 & 35.71 & 3 & 16.66 & 2 & 9.52 \\
\hline $\mathbf{4 1 - 5 0}$ & 24 & 28.57 & 6 & 33.33 & 2 & 9.52 \\
\hline $\mathbf{5 1 - 6 0}$ & 4 & 4.76 & 1 & 5.55 & 1 & 4.76 \\
\hline $\mathbf{6 1 - 7 0}$ & 5 & 5.95 & 1 & 5.55 & 0 & 0 \\
\hline $\mathbf{7 1 - 8 0}$ & 3 & 3.57 & 1 & 5.55 & 0 & 0 \\
\hline Total & 84 & & 18 & & 21 & \\
\hline
\end{tabular}

Table 3: Gender wise distribution of patients studied.

\begin{tabular}{|lllll|} 
Type of swellings & $\begin{array}{l}\text { No. of male } \\
\text { patients }\end{array}$ & $\begin{array}{l}\text { \% of male } \\
\text { patients }\end{array}$ & $\begin{array}{l}\text { No. of female } \\
\text { patients }\end{array}$ & $\begin{array}{l}\text { \% of female } \\
\text { patients }\end{array}$ \\
\hline Thyroid swelling & 8 & 9.52 & 76 & 90.47 \\
\hline Salivary gland swelling & 9 & 50 & 9 & 50 \\
\hline Other swelling & 7 & 33.33 & 14 & 66.66 \\
\hline Total & 24 & 19.51 & 99 & 80.48 \\
\hline
\end{tabular}

Table 4: Clinical diagnosis of 123 patients.

\begin{tabular}{|lll|}
\hline Clinical diagnosis & No. of patients & Percentage (\%) \\
\hline Thyroid swellings & 59 & 47.96 \\
\hline Colloid goitre & 17 & 13.82 \\
\hline Solitary thyroid nodule & 7 & 5.69 \\
\hline Multinodular goitre & 1 & 0.81 \\
\hline Thyroiditis & & \\
\hline Salivary gland swellings & 7 & 5.69 \\
\hline Chronic sialoadenitis & 7 & 5.69 \\
\hline Pleomorphic adenoma & 2 & 1.62 \\
\hline Ranula & 1 & 0.81 \\
\hline Cystic lesion & 1 & 0.81 \\
\hline Wartins tumour & & \\
\hline Other swellings & 9 & 7.31 \\
\hline Cervical lympadenopathy & 4 & 3.25 \\
\hline Thyroglossal cyst & 3 & 2.43 \\
\hline Lipoma & 2 & 1.62 \\
\hline Epidermal cyst & 1 & 0.81 \\
\hline Branchial cyst & 1 & 0.81 \\
\hline Dermoid cyst & 1 & 0.81 \\
\hline Sebaceous cyst & & \\
\hline
\end{tabular}

On studying clinical symptoms of 123 patients, it was found that $94.30 \%$ of patients had complaints of swelling over neck with no other symptoms, $3.25 \%$ of patients had complaints of dysphagia, $1.62 \%$ patients had complaints of swelling with difficulty in breathing and $0.81 \%$ patients had swelling with hoarseness of voice. On studying consistency of neck masses it was found that 111 patients had swelling firm in consistency $(90.24 \%)$, in 9 patients it was cystic $(7.31 \%)$, whereas in 3 patients it was soft comprising $2.43 \%$.
In our study of 123 patients $68.28 \%$ of benign neck swelling was of thyroid, $14.63 \%$ of swelling was of salivary gland and $17.07 \%$ were other neck swelling.

It was observed that, out of 84 cases of thyroid maximum number of patients was of colloid goitre i.e., 71\%, followed by solitary thyroid nodule $14.28 \%$, multinodular goitre comprising $11.68 \%$, and thyroiditis $2.59 \%$. 
Table 5: FNAC and USG efficacy of all swellings.

\begin{tabular}{|c|c|c|c|c|c|c|c|}
\hline $\begin{array}{l}\text { HPE-> } \\
\text { FNAC } \downarrow\end{array}$ & Benign & Non benign & Total & $\begin{array}{l}\text { HPE-> } \\
\text { USG } \downarrow\end{array}$ & Benign & Non benign & Total \\
\hline Benign & 84 & 4 & 88 & Benign & 85 & 7 & 92 \\
\hline Non benign & 9 & 26 & 35 & Non benign & 10 & 21 & 31 \\
\hline & 93 & 30 & 123 & & 95 & 28 & 123 \\
\hline
\end{tabular}

Table 6: Efficacy of FNAC and USG in thyroid swellings.

\begin{tabular}{|llllllll|}
\hline HPE $->$ & Benign & Non benign & Total & $\begin{array}{l}\text { HPE-> } \\
\text { USG } \downarrow\end{array}$ & Benign & Non benign & Total \\
\hline Benign & 63 & 1 & 64 & Benign & 60 & 3 & 63 \\
\hline Non benign & 4 & 16 & 20 & Non benign & 7 & 14 & 21 \\
\hline & 67 & 17 & 84 & & 67 & 17 & 84 \\
\hline
\end{tabular}

Table 7: FNAC and USG efficacy in salivary gland swellings.

\begin{tabular}{|llllllll|}
\hline HPE--> & Benign & Non benign & Total & $\begin{array}{l}\text { HPE-> } \\
\text { USG } \downarrow\end{array}$ & Benign & Non benign & Total \\
\hline Benign & 10 & 1 & 11 & Benign & 12 & 2 & 14 \\
\hline Non benign & 2 & 5 & 7 & Non benign & 1 & 3 & 4 \\
\hline & 12 & 6 & 18 & & 13 & 5 & 18 \\
\hline
\end{tabular}

Table 8: FNAC and USG efficacy in other neck swellings.

\begin{tabular}{|llllllll|}
\hline HPE-> & Benign & Non benign & Total & $\begin{array}{l}\text { HPE-> } \\
\text { USG } \downarrow\end{array}$ & Benign & Non benign & Total \\
\hline Benign & 11 & 2 & 13 & Benign & 13 & 2 & 15 \\
\hline Non benign & 3 & 5 & 8 & Non benign & 2 & 4 & 6 \\
\hline & 14 & 7 & 21 & & 15 & 6 & 21 \\
\hline
\end{tabular}

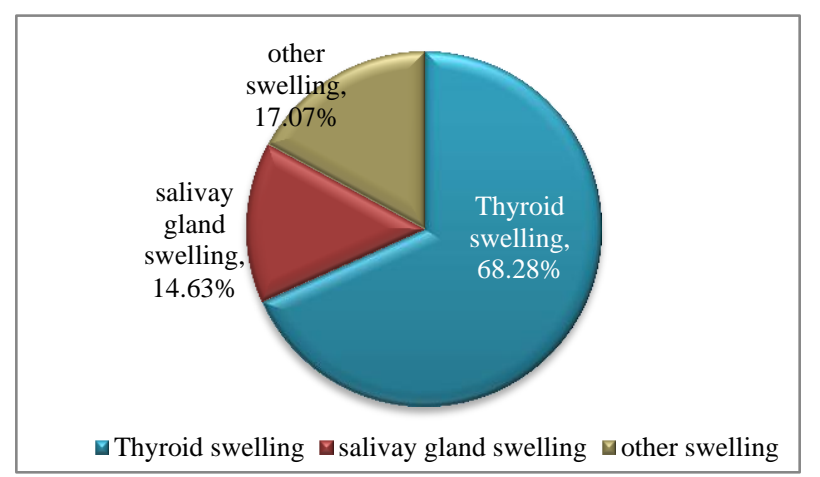

Figure 1: Types of benign neck masses.

In patients with salivary gland swellings $38.88 \%$ patients were of chronic sialoadenitis and pleomorphic adenoma, $11.11 \%$ patients were of Ranula, $5.55 \%$ patients of Wartins tumour, and $5.55 \%$ patients of cystic lesion in parotid gland.

Out of 21 patients of other neck swellings $42.85 \%$ were cervical lymphadenopathy, $14.28 \%$ of lipoma, $19.04 \%$ of thyroglossal cyst, $9.52 \%$ of epidermal cyst and 1 each patient of dermoid cyst, branchial cyst, sebaceous cyst i.e., $4.76 \%$.
On observing anatomical site of swelling, maximum number of the swellings were in midline i.e., $44.71 \%$. In $16.26 \%$ patients the swelling was upper lateral, in $15.44 \%$ patients the swelling was midlateral, in $13.82 \%$ patients swelling was lower lateral, in 5.69\% patients the swelling was submandibular, in $2.43 \%$ patients swelling was submental, and in posterior triangle it was $1.62 \%$.

\section{Correlation of usg and fnac reports of all swellings with hpe}

Comparision of sonography report of all swellings with that of hpe

- Similar to HPE reports- $77.23 \%$.

- Not similar to HPE reports- $18.69 \%$.

- Inconclusive reports- $4.06 \%$.

Comparision of fnac report of total swellings with that of hpe

- Similar to HPE reports- $85.36 \%$.

- Not similar to HPE reports- $13 \%$.

- Inconclusive reports- $1.62 \%$. 
Difference in findings of FNAC and HPE in our study may be due to differences in the method of aspiration of the neck lump. In our study, blind FNAC was performed by different technicians without ultrasound guidance.

Table 5 shows,

- Sensitivity of FNAC of all swellings, $\{\mathrm{TP} /(\mathrm{TP}+\mathrm{FN}) \times 100=(84 / 93) \times 100\}=90.32 \%$.

- Specificity of FNAC of all swellings, $\{\mathrm{TN} /(\mathrm{TN}+\mathrm{FP}) \times 100)=(26 / 30) 100\}=86.66 \%$.

- Diagnostic accuracy of FNAC of all swellings, $\{\mathrm{TN}+\mathrm{TP} / \mathrm{TOTAL} \times 100\}=(84+26) / 123 \times 100\}$ $=89.43 \%$.

- Sensitivity of USG in all swellings, $\{\mathrm{TP} /(\mathrm{TP}+\mathrm{FN}) \times 100=85 / 95 \times 100\}=89.47 \%$.

- Specificity of USG in all swellings, $\{\mathrm{TN} /(\mathrm{TN}+\mathrm{FP})=21 / 28 \times 100\}=75 \%$.

- Diagnostic accuracy of USG in all swellings, $\{\mathrm{TN}+\mathrm{TP} / \mathrm{TOTAL} \times 100\}=(85+21) / 123 \times 100\}$ $=86.84 \%$.

Table 6 shows,

- Sensitivity of FNAC in thyroid swellings, $\{\mathrm{TP} /(\mathrm{TP}+\mathrm{FN}) \times 100=(63 / 67) \times 100\}=93.44 \%$.

- Specificity of FNAC in thyroid swellings, $\{\mathrm{TN} /(\mathrm{TN}+\mathrm{FP}) \times 100=(16 / 17) \times 100\}=94.11 \%$.

- Diagnostic accuracy of FNAC in thyroid swellings, $\{\mathrm{TN}+\mathrm{TP} / \mathrm{TOTAL} \times 100\}=(63+16) / 84 \times 100\}=94.04$.

- Sensitivity of USG in thyroid swellings, $\{\mathrm{TP} /(\mathrm{TP}+\mathrm{FN}) \times 100=60 / 79 \times 100\}=89 \%$.

- Specificity of USG in thyroid swellings, $\{\mathrm{TN} /(\mathrm{TN}+\mathrm{FP})=4 / 5 \times 100\}=80 \%$.

- Diagnostic Accuracy of USG in thyroid swellings, $\{\mathrm{TN}+\mathrm{TP} / \mathrm{TOTAL} \times 100\}=(60+14) / 84 \times 100\}=$ $76.19 \%$.

Table 7 shows,

- Sensitivity of FNAC in salivary gland swellings, $\{\mathrm{TP} /(\mathrm{TP}+\mathrm{FN}) \times 100=10 / 12 \times 100\}=82 \%$.

- Specificity of FNAC in salivary gland swellings, $\{\mathrm{TN} /(\mathrm{TN}+\mathrm{FP}) \times 100=5 / 6 \times 100\}=83.33 \%$.

- Diagnostic accuracy of FNAC in salivary gland swellings,

$\{\mathrm{TN}+\mathrm{TP} / \mathrm{TOTAL} \times 100\}=(10+5) / 18 \times 100\}=83 \%$.

- Sensitivity of USG in salivary gland swellings, $\{\mathrm{TP} /(\mathrm{TP}+\mathrm{FN}) \times 100=12 / 13 \times 100\}=92.30 \%$.

- Specificity of USG in salivary gland swellings, $\{\mathrm{TN} /(\mathrm{TN}+\mathrm{FP})=3 / 5 \times 100\}=85.7 \%$.

- Diagnostic accuracy of USG in salivary gland swellings, $\quad\{\mathrm{TN}+\mathrm{TP} / \mathrm{TOTAL} \times 100\}=(12+3) / 18 \times 100\}$ $=83.33 \%$.

Table 8 shows,

- Sensitivity of FNAC in other neck swellings, $\{\mathrm{TP} /(\mathrm{TP}+\mathrm{FN}) \times 100=11 / 14 \times 100\}=78.57 \%$.
- Specificity of FNAC in other neck swellings, $\{\mathrm{TN} /(\mathrm{TN}+\mathrm{FP}) \times 100=5 / 7 \times 100\}=71.42 \%$.

- Diagnostic accuracy of FNAC in other neck swellings, $\quad\{\mathrm{TN}+\mathrm{TP} / \mathrm{TOTAL} \times 100=(11+5) / 21 \times 100\}$ $=76.19 \%$.

- Sensitivity of USG in other neck swellings, $\{\mathrm{TP} /(\mathrm{TP}+\mathrm{FN}) \times 100=13 / 15 \times 100\}=87.50 \%$.

- Specificity of USG in other neck swellings $=75 \%$.

- Diagnostic accuracy of USG in other neck swellings, $\{\mathrm{TN}+\mathrm{TP} / \mathrm{TOTAL} \times 100\}=(13+4) / 21 \times 100\}=83.33 \%$.

\section{DISCUSSION}

The present study was carried out at the department of ENT, from January 2016 to June 2017. Out of 123 cases clinically evaluated, 84 were thyroid swellings, 18 were salivary gland swellings and 21 were other swellings out of which 9 were lymph node swellings. $80.48 \%$ were female patients and $19.51 \%$ were male patients. Maximum number of patients was between the age group $31-40$ years $(28.45 \%)$ followed by $26.05 \%$ in $41-50$ years. Maximum no. of patients presented with complaints of swelling over neck with no other symptoms (94.30\%), swelling was in midline neck $(44.71 \%)$, firm (90.24\%). Thyroid swelling aspiration was carried on in 84 cases, which was the commonest swelling in our study. Out of 84 thyroid cases, cytology reports of 65 patients were similar to HPE report. 19 were not similar to HPE.

\section{Ultrasound in diagnosis of neck masses}

The role of USG in evaluation of neck region is becoming increasingly important due to the availability of high frequency (7.5 to $15 \mathrm{MHZ}$ ) probes, which permit visualization of more subtle anatomical and pathological details. ${ }^{8}$ The patient's age, the location, size and duration of mass are important pieces of information in the diagnosis of the neck masses. High resolution B-mode sonography has improved in the past few years and has become a very valuable tool in the diagnosis of the disease of the head and neck.

In study of Thapa et al of hundred patients (70 female and 30 male) showed USG scanning was $100 \%$ sensitive and $91 \%$ specific for the diagnosis of benign thyroid nodules with positive predicitive value (PPV) of $97 \%$ and negative predictive value (NPV) of $100 \%(\mathrm{p}=0.0) .{ }^{9}$ For the diagnosis of the malignant thyroid nodule USG is $91 \%$ sensitive and $100 \%$ specific with PPV of 100 percent and NPV of $97 \%(\mathrm{p}=0.0)$. Similarly, the USG diagnosis was 100 percent sensitive and $81 \%$ specific for malignant lymphnode with PPV of $81 \%$ and NPV of $100 \%(\mathrm{p}=0.0003)$.

Solbiati et al reported peripheral and egg shell calcification were more common and reliable features of benign nodule and microcalcification for malignant nodule. ${ }^{10}$ In the study $47 \%$ of benign nodules, $9 \%$ shows coarse calcification, $27 \%$ of malignant nodules show 
microcalcification, and 2 percent shows eggshell calcification.

In study of Sardar et al of 73 subjects the sonographic consistency of neck masses shows $65.8 \%$ solid masses, $15.1 \%$ cystic masses and $19.2 \%$ are mixed consistency. Comparison of diagnostic accuracy of ultrasonography with FNAC revealed that in infective neck masses diagnostic accuracy is $27.4 \%$ on sonography as compared to $24.7 \%$ on FNAC. Cystic neck mass diagnostic accuracy was $19.2 \%$ on both FNAC as well as sonography. The diagnostic accuracy in benign neck masses showed $26.0 \%$ on FNAC and $37.0 \%$ on sonography. The sensitivity of USG was $100 \%$ and specificity was $85.2 \% .^{11}$

In present study of 123 patients in a tertiary care hospital, sonographic consistency showed $57.72 \%$ swelling were solid, $39.83 \%$ swelling were mixed and $2.43 \%$ swelling were purely cystic. 112 patients out of 23 patients presented with single swelling, maximum swellings were isoechoic 52.03\%, 102 swelings had well defined margins and $31.70 \%$ swelling had coarse calcification. Micro calcification was not seen in any thyroid swelling.

The sensitivity of ultrasound for all swellings was $89.47 \%$, specificity $75 \%$ and diagnostic accuracy $86.84 \%$. 85 swellings which were clinically palpable as benign were benign on histopathology, whereas 7 swellings which were benign on ultrasound turned out be malignant on histopathology. Follow up of all patients was taken post operatively on 1 st month, 3rd month and 6 th month. One patient of ranula showed recurrence at 6th month.

On studying ultrasonographic features in present study of 123 patients it was found that, the masses were solitary in 112 patients $(90.36 \%)$ whereas in 11 patients $(9.64 \%)$ it were multiple. The masses were purely cystic in 3 patients $(2.43 \%)$, mixed solid \&cystic in 49 patients $(39.83 \%)$ and solid in 71 patients $(57.72 \%)$. The masses were hyperechoic in 32 patients $(26.01 \%)$, isoechoic in 64 patients $(52.03 \%)$, and hypoechoic in 27 patients $(21.95 \%)$. The margins were well defined in 102 patients $(82.92 \%)$, and poorly defined in 21 patients $(17.07 \%)$. It was found that 3 patients $(2.43 \%)$ had eggshell calcification, 39 patients $(31.70 \%)$ had coarse whereas 81 patients $(65.85 \%)$ had no calcification.

On comparing the efficacy of USG of present study with other studies it was found that in present study that the sensitivity of USG is $89.47 \%$ with specificity of $75 \%$. In study of Sardar et al conducted in 2009 sensitivity of USG was $100 \%$ with specificity of $85.2 \% .^{25}$ In study of Thapa conducted in 2008, sensitivity of USG was $100 \%$ with specificity of $91 \%{ }^{3}$ In study of Solbiati et al conducted in 1992 ,sensitivity of USG was 36\% with specificity of $91 \% .^{10}$
Our study evaluated 123 patients we found that overall sensitivity of FNAC in the diagnosis of neck masses to be $90.32 \%$ and specificity to be $86.66 \%$. 84 swellings which were benign on fine needle aspiration cytology were benign on histopathology. 4 swellings which were diagnosed as benign turned out malignant on histopathology. FNAC cannot differentiate between follicular adenoma and follicular carcinoma of thyroid. 2 swellings were diagnosed as follicular adenoma were follicular carcinoma on histopathology. The sensitivity of FNAC for thyroid swellings in my study is $93.44 \%$, specificity is $94.11 \%$ and diagnostic accuracy is $94.04 \%$.

Study done by Pradeep et al of 100 patients, maximum no. of patients were thyroid swellings followed by lymph node swellings. ${ }^{12} 60 \%$ of patients were females. $43 \%$ of patients presented with midlne neck swelling. The sensitivity of FNAC was $71.43 \%$, specificity was $98.85 \%$ with diagnostic accuracy for neck swelling 96\%. The sensitivity of FNAC for thyroid swelling was $75 \%$ specificity was $97.29 \%$ and accuracy was $97.5 \%$.

Study by Soni et al had sensitivity of $83.01 \%$ and specificity of $78.94 \% .{ }^{13}$ Out of the 59 patients, 28 were of neck nodes, 14 were thyroid, 13 were of salivary gland masses and 4 were other types of neck masses, while in our study out of 123 cases thyroid swellings were commonest i.e., 84, salivary gland swellings were 18 and other swellings including cervical lymphadenopathy were 21.

A retrospective study was conducted between February 2004 to August 2005 by Chauhan et al, fine needle aspiration diagnosis was correlated with detail of relevant clinical findings and investigations. ${ }^{14}$ Patients between the ages of 1 to 80 years were taken into the study. A total of 100 patients with a head and neck swelling underwent FNAC. Out of 100 fine needle aspiration procedures, $51 \%$ were of lymph node, $20 \%$ were thyroid, $15 \%$ from salivary gland, $08 \%$ from soft tissue and $06 \%$ were miscellaneous swellings, while in our study out of 123 neck swellings, thyroid swellings were $68.28 \%$, $7.31 \%$, were lymph nodes (excluding those lymphnode swellings occurring during acute neck infections, tubercular lymphadenopathy and metastatic lymphnodes; as per exclusion criteria of my study) $14.63 \%$ were salivary gland swellings and other swellings were $9.75 \%$. Howlett et al studied a total of 276 patients and found FNAC of neck nodes to have a sensitivity of $89 \%$ and a specificity of $57 \%$ while in our study sensitivity is $93.44 \%$ and specificity is $94.11 \%$, for thyroid masses, and for salivary glands, the sensitivity was $64 \%$ and specificity was $100 \%$ while in our study the sensitivity of FNAC for salivary gland swelling is $82 \%$ and specificity is $83.33 \%$. $^{15}$

Tilak et al studied 550 patients and found the overall sensitivity of FNAC for neck masses to be $90.91 \%$ which is almost similar that our study and specificity to be $93.18 \%$ which is lesser than our study which is $86.66 \%$. $^{16}$ 
Difference in the specificity between our study and others may be due to differences in the method of aspiration of the neck lump. In our study, blind FNAC was performed by different technicians without ultrasound guidance.

In Howlett et al study, ultrasound guided FNAC was used in $50 \%$ of the thyroid group and a few parotid patients. ${ }^{15}$ The differences might also be explained by differences in the patient population. In India, most patients are illiterate and unaware of their health problems until they are at an advanced stage. The majority of patients present with a huge neck mass which is obvious and easy for the cytopathologist to locate with FNAC without the use of ultrasound guidance. In addition, in such large lesions there may well be a sampling error within the mass itself with different regions of the mass having different grades of pathology.

On comparing FNAC results of present study with other studies it was that in present study that the sensitivity of FNAC is $90.32 \%$ with specificity of $86.66 \%$. In study of Kumarsingh et al, conducted in 2012-13 sensitivity of FNAC was $71.43 \%$, with specificity of $98.85 \%$. $^{12}$ In study of Razmpa et al conducted in 2000 sensitivity of FNAC was $92.3 \%$ with specificity of $88.1 \% .^{26}$ In study of Abdulqadir et al conducted in 2003 sensitivity of FNAC was $90 \%$ with specificity of $100 \% .^{21}$

\section{CONCLUSION}

In our study, 123 patients were studied and it was observed that most of benign swellings of neck were arising from thyroid gland, common in females (Ratio 9:1) in age group of 31-40 yrs. USG and fine needle aspiration cytology offers a simple method of diagnosis of neoplastic and non neoplastic lesions in the neck.

In our study, accuracy of FNAC $(89.43 \%)$ is more as compared to USG (86.84\%). Fine needle aspiration cytology of neck masses with clinical correlation and ultrasonography provide most useful information to surgeon to determine the further mode of management.

Hence we conclude from present study, that fine needle aspiration cytology is a safe, simple and more accurate than USG that can be done in diagnosing wide range of neck swellings. Probably USG guided fine needle aspiration cytology will be better investigation one can ask for. However confirmatory and accurate diagnosis is given by histopathology.

\section{ACKNOWLEDGEMENTS}

As it is said that, gratitude, when expressed in words, it's only half its acknowledgement. Having searched extensively through the pages of therausus and oxford, I could not find the words to express my thanks with a great sense of gratitude to my respected teacher and guide Dr. Surendra Gawarle, Professor and Head, Department of ENT, Shri Vasantrao Naik Government
Medical College and Hospital, Yavatmal, under whose guidance and supervision, I had the opportunity to carry out this work. I am also grateful to Dr. Prashant Keche, Associate Professor, Cancer Hospital, GMCH Aurangabad, for his constant support, encouragement which led to completion of this work. I bow in gratitude to the The almighty God for making this humble attempt to success.

\section{Funding: No funding sources \\ Conflict of interest: None declared}

Ethical approval: The study was approved by the Institutional Ethics Committee

\section{REFERENCES}

1. Haynes J, Arnold KR, Aguirre-Oskins C, Chandra S. Evaluation of neck masses in adults. Am Fam Physician. 2015;91(10):698-706.

2. Pynnonen MA, Colandrea M, Finestone SA, O'Connor SS. Plain language summary: evaluation of the neck mass in adults. Otolaryngol Head Neck Surg. 2017;157(3):372-82.

3. Thapa NB. Ultrasound in the diagnosis of neck masses. J Nepal Health Res Counc. 2008; 651-7.

4. Bomeli SR, LeBeau SO, Ferris RL. Evaluation of a thyroid nodule. Otolaryngol Clin North Am. 2010;43(2):229-38.

5. Sohn JH, Jung EH, Park HR. Cytologic findings of infectious mononucleosis lymphadenitis: a report of four cases. Korean J Pathol. 1998;9(2):227-321.

6. Burnand KG, Young AE, Lucas J, Rolands BJ, Scholefield J. The new Aird's companion in surgical studies. 3rd edition. China: Elsevier. 2005; 6-8.

7. Watkinson JC, Wilson JA, Gaze M, Stell PM, Maran AGD. Stell and Maran's head and neck surgery, Chapter 2. 4th edition. ButterworthHeinemann: Oxford; 2000: 20-21.

8. Yousem DM, Kraut MA, Chalian AA. Major salivary gland imaging. Radiology. 2000;216(1):1929.

9. Thapa NB. Ultrasound in the diagnosis of neck masses. J Nepal Health Res Counc. 2008; 3-4.

10. Solbiati L. The thyroid gland. Diagnos Ultrasound. 1992;11:703-55.

11. Sardar Q, Qureshi M, Ch K. Predictive value of ultrasonography in the differential diagnostics of adult neck masses. 2009;23(1):19-27.

12. Kumar Singh P, Kumar A, Kumar D. Clinicopathological study of neck masses in patients attending ENT out patient department of Rajendra Institute of Medical Sciences, Ranchi. IOSR J Dent Med Sci. 2017;16(1):2279-861.

13. Soni S, Pippal SK, Yashveer B, Srivastava P. Efficacy of fine needle aspiration in diagnosis of neck masses. World articles of Ear Nose and Throat.2010;3-1.

14. Chauhan S, Rathod D, Joshi DS. FNAC of swellings of head and neck region. Indian Journal of Applied Basic Medical Sciences. 2011;13:1-6. 
15. Howlett DC, Harper B, Quante M, Berresford A, Morley M, Grant J, et al. Diagnostic adequacy and accuracy of fine needle aspiration cytology in neck lump assessment: results from a regional cancer network over a one year period. J Laryngol Otol. 2007;121(6):571-9.

16. Tilak V, Dhaded AV, Jain R. Fine needle aspiration cytology of head and neck masses. Indian J Pathol Microbiol. 2002;45(1):23-9.

17. Soni S, Pippal SK, Yashveer B, Srivastava P. Efficacy of fine needle aspiration in diagnosis of neck masses. World articles of Ear Nose and Throat. 2010;1-3.

18. Koischwitz D, Gritzmann N. Ulrasound of the neck. Radiol Clin North Am. 2000;38:1029-45.

19. Russel RCG, William NS, Bulstrode CJK. Bailey and Love's short practice of surgery. 24th edition. London: Arnold; 2004: 4-6.

20. Burnand KG, Young AE, Lucas J, Rolands BJ, Scholefield J. The new Aird's companion in surgical studies. 3rd edition. China:Elsevier; 2005: 6-8.

21. Abdulqadir M, Zangana S, Abu B, Sherwan AG. A comparative study between cytological and histopathological findings in thyroid swellings in Erbil city. Adv Med Dent Sci. 2009;3(1):29-34.
22. Gleeson M, Scott Brown's Otorhinolaryngology, Head and neck surgery. Hodder Arnold (ed). 7th edition. Volume 2. Chapter 137 by Chris R Jennings. 1739-1753.

23. Bomeli SR, LeBeau SO, Ferris RL. Evaluation of a thyroid nodule. Otolaryngol Clin North Am. 2010;43(2):229-38.

24. Tatomirovic Z, Skuletic V, Bokun R, Trimcev J, Radic O, Cerovic S, et al. Fine needle aspiration cytology in the diagnosis of head and neck masses: accuracy and diagnostic problems. J BUON. 2009;14(4):653-9.

25. Sardar Q, Qureshi M, Ch K. Predictive value of ultrasonography in the differential diagnostics of adult neck masses. 2009;23(1):19-27.

26. Razmpa E, Ghanaati H, Naghibzadeh B, Mazloom $\mathrm{P}$, Kashfi A. Comparison of ultrasound findings with cytologic results in thyroid nodules. Acta Med Iran. 2002;40(3):146-51.

Cite this article as: Garud $\mathrm{P}$, Gawarle S, Keche P. Clinicopathological evaluation of benign neck masses with emphasis on correlation of preoperative ultrasound and cytology with postoperative histopathology in tertiary care hospital. Int J Otorhinolaryngol Head Neck Surg 2019;5:946-53. 